\title{
The Role of Structure in the Biology of Interferon Signaling
}

\author{
Mark R. Walter* \\ Department of Microbiology, University of Alabama at Birmingham, Birmingham, AL, United States
}

Interferons (IFNs) are a family of cytokines with the unique ability to induce cell intrinsic programs that enhance resistance to viral infection. Induction of an antiviral state at the cell, tissue, organ, and organismal level is performed by three distinct IFN families, designated as Type-I, Type-II, and Type-III IFNs. Overall, there are 21 human IFNs, (16

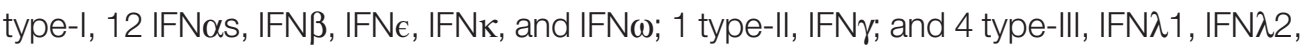
IFN $\lambda 3$, and IFN $\lambda 4$ ), that induce pleotropic cellular activities essential for innate and adaptive immune responses against virus and other pathogens. IFN signaling is initiated by binding to distinct heterodimeric receptor complexes. The three-dimensional structures of the type-I (IFN $\alpha /$ IFNAR1/IFNAR2), type-II (IFN $\gamma /$ IFNGR1/IFNGR2), and type-III (IFN $\lambda 3 /$ IFN $\lambda R 1 /$ IL1OR2) signaling complexes have been determined. Here, we

OPEN ACCESS

Edited by:

Laura Maggi,

University of Florence, Italy

Reviewed by:

Gideon Schreiber,

Weizmann Institute of Science, Israel Sandra Pellegrini,

Institut Pasteur, France

${ }^{*}$ Correspondence:

Mark R. Walter

walter@uab.edu

Specialty section:

This article was submitted to

Cytokines and Soluble

Mediators in Immunity,

a section of the journal

Frontiers in Immunology

Received: 15 September 2020

Accepted: 19 October 2020

Published: 12 November 2020

Citation:

Walter MR (2020)

The Role of Structure in the Biology of Interferon Signaling.

Front. Immunol. 11:606489. doi: 10.3389/fimmu.2020.606489 highlight similar and unique features of the IFNs, their cell surface complexes and discuss their role in inducing downstream IFN signaling responses.

Keywords: interferon, IFN, type-I, type-II, type-III, receptor complex, IFN signaling, structure

\section{INTRODUCTION}

IFNs were discovered more than 60 years ago (1957) as substances that protect cells from viral infection $(1,2)$. Based on their sensitivity to $\mathrm{pH}$, IFNs were designated as either type-I ( $\mathrm{pH}$ stable) or type-II ( $\mathrm{pH}$ sensitive) $(2,3)$. Characterization of their distinct amino acid sequences and crystal structures $(4,5)(6-8)$ further validated the classification of IFN $\alpha / \beta$ and IFN $\gamma$ as type-I and type-II IFNs, respectively. The type-I family expanded (9) to include 12 IFNos (10-13) encoded by 13 genes (IFN $\alpha 1 / 13$ encode the same protein), IFN $\beta$, IFNe (14), IFNא (15), and IFN $\omega$ (16). Genome analysis in 2003 identified a new type-III IFN family (IFN $\lambda$ s) $(17,18)$, which by sequence and subsequent structure analysis (19) were similar to IL10 family cytokines (12, 20-22), in particular IL-22 (23, 24). With the discovery of IFN $\lambda 4$ in 2013 (25), a total of 21 IFNs (Table 1) exhibit not only antiviral activity, but anti-tumor actions, and the ability to modulate the adaptive immune response.

The pleotropic biological activities of the three IFN families are initiated by binding and subsequent assembly of heterodimeric receptor complexes on the cell membrane (Table 1). The 16 type-I IFNs bind and signal through the IFNAR1 and IFNAR2 receptor complex, type-II IFN $\gamma$ binds to IFNGR1 and IFNGR2 chains, and the type-III IFNs signal through IFN $\lambda$ R1 and IL-10R2 receptor chains. Each receptor heterodimer consists of a high affinity receptor chain (e.g., IFNAR2, IFNGR1, IFN $\lambda$ R1) and a low IFN affinity receptor chain (IFNAR1, IFNGR2, IL10R2). The high and low affinity receptors exhibit $\mathrm{nM}$ and $\mu \mathrm{M} / \mathrm{mM}$ affinity, respectively, for their cognate IFNs (26-30). Despite variable affinities, the high and low affinity type-I and type-II receptors are specific for their cognate IFN family members. In contrast, IFN $\lambda$ R1 is specific for type-III IFN $\lambda$ family members, but 
TABLE 1 | IFN families and their receptor complexes.

\begin{tabular}{|c|c|c|c|c|c|c|c|c|c|}
\hline & High Affinity Receptor & Low Affinity Receptor & & & & IFNs & & & \\
\hline \multirow[t]{2}{*}{ Type-I IFNs } & IFNAR2 & IFNAR1 & $\begin{array}{l}\text { IFN } \alpha 1 / 13^{*} \\
\text { IFN } \alpha 10 \\
\text { IFNא, }\end{array}$ & $\begin{array}{l}\text { IFNo2, } \\
\text { IFN } \alpha 14, \\
\text { IFN } \omega\end{array}$ & $\begin{array}{l}\text { IFN } \alpha 4 \\
\text { IFN } \alpha 16\end{array}$ & $\begin{array}{l}\text { IFN } \alpha 5 \\
\text { IFN } \alpha 17 \text {, }\end{array}$ & $\begin{array}{l}\text { IFN } \alpha 6 \\
\text { IFN } 221\end{array}$ & $\begin{array}{l}\text { IFN } \alpha 7 \\
\text { IFN } \beta \text {, }\end{array}$ & $\begin{array}{l}\text { IFN } \alpha 8 \text {, } \\
\text { IFNe, }\end{array}$ \\
\hline & JAK1 & TYK2 & & & & & & & \\
\hline \multirow[t]{2}{*}{ Type-II IFNs } & IFNGR1 & IFNGR2 & $\mathrm{IFN} \gamma$ & & & & & & \\
\hline & JAK1 & JAK2 & & & & & & & \\
\hline \multirow[t]{3}{*}{ Type-III IFNs } & IFNLR1 & & IFN $\lambda 1$ & IFNג2, & IFNג3, & $\mathrm{IFN} \lambda 4$ & & & \\
\hline & & IL10R2 & IFN $\lambda 1$ & IFN $\lambda 2$ & IFN $\lambda 3$ & IFN $\lambda 4$ & IL10, & IL22, & IL26 \\
\hline & JAK1 & TYK2 & & & & & & & \\
\hline
\end{tabular}

*IFN $\alpha 1 / 13$ encode the same amino acid sequence [(see 9)].

the low affinity IL-10R2 chain is a shared receptor that also participates in IL10, IL22, and IL26 signaling complexes (12, 31-33).

IFN receptor complex formation activates Janus kinases (JAKs) that initiate IFN-mediated intracellular signaling cascades (34-38). The JAKs constitutively associate with the intracellular domains (ICDs) of the IFN receptors through noncovalent interactions (Table 1). Type-I and type-III IFN receptors use the same JAKs for signal transduction. The high affinity IFNAR2 and IFN $\lambda$ R1 receptors associate with JAK1, while low affinity IFNAR1 and IL10R2 associate with TYK2. In contrast, type-II IFNGR1 and IFNGR2 associate with JAK1 and JAK2, respectively $(39,40)$. The ICDs of the low affinity receptors are 69-100 amino acids long and their main purpose appears to be to bind their respective kinases for activation upon receptor complex formation. The high affinity receptor ICDs range from 223 to 271 amino acids in length and contain multiple tyrosine residues that upon phosphorylation by the JAKs, recruit STATs that become phosphorylated themselves, and translocate to the nucleus where they activate interferon-stimulated genes (ISGs) $(40,41)$. In addition to using the same JAKs, type-I and type-III IFNs induce the same STAT1/STAT2/IRF9, ISGF3 transcription complex (40-42). IFN $\gamma$ activates phospho-STAT1 homodimers, but not ISGF3, which is reflected in the $\sim 1,000$-fold lower antiviral activity of IFN $\gamma$ compared to the type-I and type-III IFNs $(43,44)$. In addition to activating distinct intracellular signaling pathways, type-I/III IFNs are produced in cells upon viral infection, or infection by other pathogens, through pattern recognition receptor pathways, including RIGI, MDA7, PKR, TLR3, TLR7, TLR9, and STING (40, 45-48). In contrast, type-II IFN $\gamma$ is produced predominantly by antigen-activated $\mathrm{T}$ lymphocytes (39). Thus, type-I/III IFNs are products of innate immune system, designed to establish direct and immediate antiviral states in cells, yet can also modulate adaptive immune responses. Type-II IFN $\gamma$ is itself a product of adaptive immunity that acts on cells of innate immunity, notably macrophages. As a potent macrophage activator, IFN $\gamma$ is essential for combating mycobacteria and other intracellular pathogens $(49,50)$. IFNGR1 deficiencies in individuals are associated with mycobacterial infections, while individuals with IFNAR2, or IFNAR1, deficiencies have had life threatening illness following vaccination with mumps, measles, and rubella (MMR) vaccines $(51,52)$. Together, these data highlight the distinct roles of these IFNs in controlling different pathogens.
While there is only one IFN $\gamma$, it is remarkable that humans encode 16 different type-I and 4 type-III IFNs that induce the same fundamental ISGF3-mediated anti-viral program in cells $(17,18,53,54)$. The necessity of this remarkable arsenal of IFNs to combat virus, and other pathogens (55-58), remains an area of intense investigation. Given the complexity of IFN signaling, this review describes the fundamental structural organization of each IFN receptor complex in generating IFN signaling responses. The main emphasis is to define how structure impacts IFN-IFN receptor affinity, specificity, and the role of the overall architecture of the complex to position receptor ICDs for intracellular JAK/STAT activation and subsequent cellular activity.

\section{Structures of the Type-I, Type-II, and Type-III IFNs}

All IFNs adopt $\alpha$-helical structures with unique up-up-downdown topology (21), relative to other $\alpha$-helix bundle proteins (Figure 1). Each IFN consists of six secondary structural elements, denoted A-F, of which helices A, C, D, and F form an anti-parallel four helix bundle. Loop elements B and E exhibit more variable secondary structures, ranging from additional helices to extended segments that pack against the edge of the four-helix bundle (helices A, C, D, and F). The $\alpha$-helices of the Type-I IFNs are long, straight, and essentially parallel to one another (Figure 1A). Despite considerable sequence diversity (35\%-95\%), all 16 IFNs adopt the same $\alpha$-helical structure (4, 5, 59-63). In contrast to type-I IFNs, type-III IFNs are comprised of shorter helices that contain several kinks, which form a more compact bundle (Figure 1B). As a result, type-III IFNs adopt structures that are more similar to the IL-10 family cytokine IL22 than to type-I IFNs $(12,19,23,24,64)$. This is interesting from a functional perspective since IL-22 induces anti-bacterial activity in the gut and skin through a tissue-restricted receptor complex of IL22R1 and IL10R2 $(22,32,65-70)$. Thus, IFN $\lambda$ s and IL-22 control viral and bacterial challenges, respectively, at barrier surfaces $(22,64,71)$. As a "mucosal IFN", IFN $\lambda$ s have been promoted as an optimal drug to treat respiratory viruses, such as Severe Acute Respiratory Syndrome Coronavirus 2 (SARS-CoV-2), which causes COVID-19 (72). However, IFN $\lambda$ signaling in mice prevents lung epithelial repair, leading to bacterial superinfections $(73,74)$. Other studies suggest type-I IFNs, not IFN $\lambda$ s, might be most efficacious and safe in treating SARS-CoV-2 (75). Overall, these studies highlight the 


\section{A}

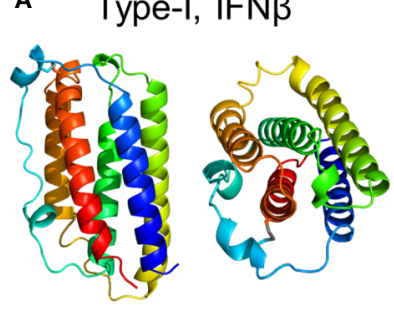

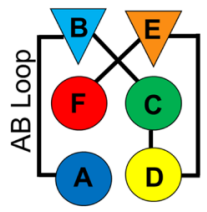

B

Type-III, IFN $\lambda 3$

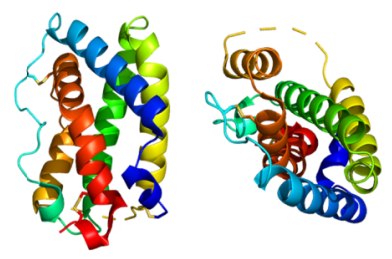

c Type-II, IFNY
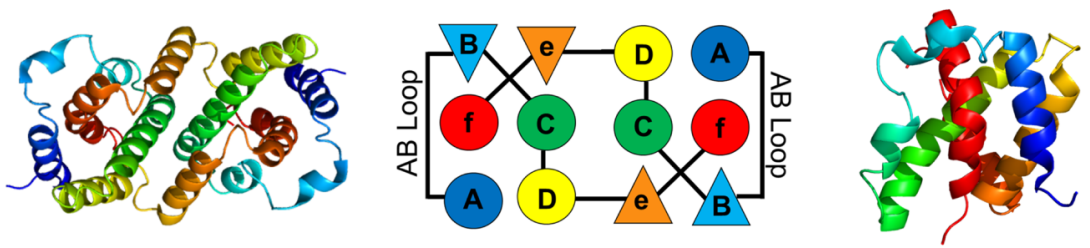

FIGURE 1 | Structures of IFN family members. Schematic, and ribbon diagrams, show the six secondary structural elements of the type-I (A), pdbid = 1AU, type-III (B), pdbid $=3 \mathrm{HHC}$, and type-II (C), pdbid = 6E3K IFNs. IFN structures are rainbow colored from the $\mathrm{N}$-terminus helix $\mathrm{A}$ (blue) to the C-terminal helix $\mathrm{F}$ (red).

complexity of IFN signaling at barrier surfaces and differences in IFN signaling outcomes in mice vs. humans.

In contrast to the monomeric type- I and type-III IFNs, IFN $\gamma$ adopts an intercalated dimer structure, where helices $\mathrm{E}$ and $\mathrm{F}$ from one chain are "swapped" with the other subunit of the dimer (Figure 1C). Like the IFN $\lambda$ s, the structure of IFN $\gamma$ is most similar to IL10, which is the founding member of the IL-10 cytokine family $(12,21,32,76-78)$. These data confirm that each IFN family adopts a distinct $\alpha$-helical scaffold, which must "handle" various amounts of sequence variation to regulate engagement of their cellular receptors. For example, there is one highly conserved type-II IFN $\gamma$ dimer, whereas there are 16 monomeric type-I IFNs (35\%-95\% sequence identity) and 4 type-III IFNs (28\%-96\% sequence identity) that exhibit variable amino acid sequence identities. This highlights the distinct mechanisms used by each IFN family to regulate biological activity. Receptor homodimerization by IFN $\gamma$, versus variable IFN/IFN-receptor contacts by monomeric type-I and type-III IFNs. These mechanisms will be reviewed in more detail below.

\section{The Type-III IFN $\lambda$ /IFN $\lambda$ R1/IL10R2 Complex}

The type-III IFN $\lambda$ receptor complex (79) exhibits the simplest architecture of the three IFN families. Monomeric IFN $\lambda$ s assemble 1:1:1 signaling complexes with high affinity IFN $\lambda$ R1 and low affinity IL10R2 receptors (Figure 2A). IFN $\lambda$ R1 and IL10R2 both consist of two $\beta$-sandwich domains (D1, D2), where the $\mathrm{D} 2$ domains are positioned closest to the membrane. IFN $\lambda \mathrm{R} 1$ binds to the IFN $\lambda$ s using five receptor loops (L2-L6) that are located at the junction of the D1 and D2 domains. The IFN $\lambda$ R1 binding loops contact IFN $\lambda$ residues located on helix $A$, the $A B$ loop, and helix F. Although differing in detail, the high affinity IFN $\lambda /$ IFN $\lambda$ R1 site-1 binding site is conserved with type-I and

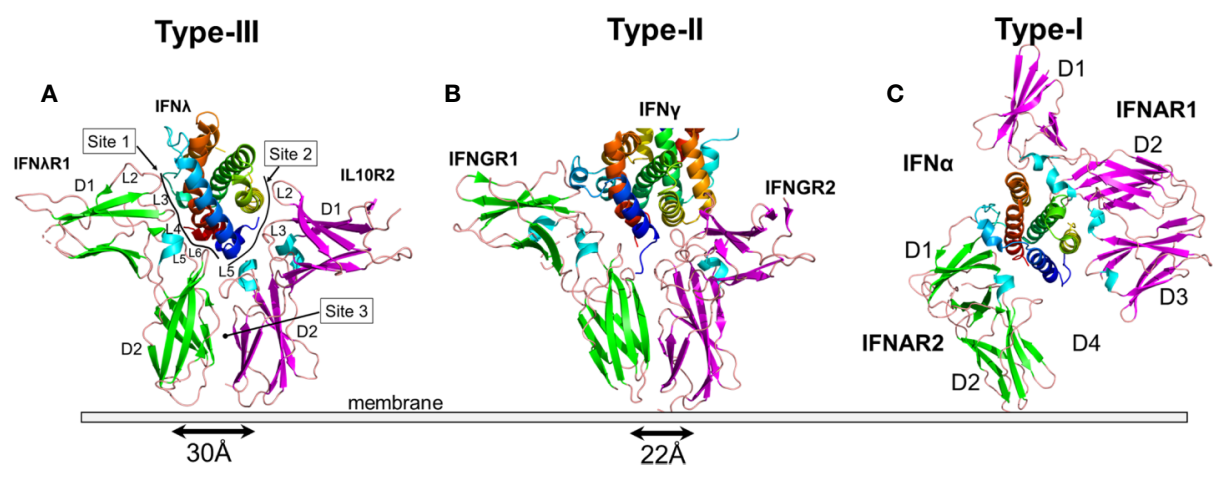

FIGURE 2 | Structures of the IFN Receptor Complexes. Ribbon diagrams of the type-III (A), pdbid = 5T5W, type-II (B), pdbid = 6E3K, and type-I (C), pdbid = 3SE4, receptor complexes. IFNs are rainbow colored as described in Figure 1 . The $\beta$-strands of the high affinity receptor chains are colored green and low affinity chains are colored magenta. For the type-II IFN $\gamma$ receptor complex, only one IFN $\gamma$ subunit is shown to emphasize the similarity of "half" of the complex with the typeIII IFN receptor complex. The separation of the C-termini of the type-III IFN $\lambda$ R1/IL-10R2 and type-II IFNGR1/IFNGR2 receptor chains, where they enter the membrane are $30 \AA$ and $22 \AA$, respectively. A D2-D4 interaction was not observed in structures of the IFN/IFNAR1/IFNAR2 complex. 
type-II high affinity receptor complexes (Figure 2). The low affinity IL10R2 binding site- 2 consists of $\mathrm{N}$-terminal IFN $\lambda$ residues, prior to the start of helix A (e.g., the pre-A region (80), also see Figure 3A), residues on helix C, and on the segment of helix D that runs parallel to the pre-A region. IL10R2 uses a subset of the same loops used by IFN $\lambda$ R1 (loops L2, L3, and L5) to contact IFN $\lambda$. Thus, the IFN $\lambda$-IL10R2 site-2 interface is discontinuous, making a smaller L2/helix D contact (site-2a) and a larger interaction between L3/L5 and IFN $\lambda$ pre-A and helix D (Site 2b).

In addition to IFN $\lambda$-IL10R2 site- 2 contacts, IL10R2 forms an additional D2-D2 site-3 interface with IFN $\lambda$ R1. Thus, the complete IL10R 2 binding site is only formed once IFN $\lambda$ binds to IFN $\lambda$ R1. This structural organization ensures IFN $\lambda$ receptor complex formation is cooperative, where the IFN $\lambda /$ IFN $\lambda$ R1 complex forms first, followed by binding of IL10R2 to site- 2 and site-3. Once formed, the assembled IFN $\lambda$ complex positions the C-terminal ends of IFN $\lambda$ R 1 and IL10R2 $30 \AA$ apart from one another, prior to entering the membrane. The combined site- 2 and site- 3 interfaces bury over $1,500 \AA$ (2) of surface area, which is more than twice the surface area buried in the high affinity IFN $\lambda 3 /$ IFN $\lambda$ R 1 site- 1 interaction. However, despite this extensive interface, there are few energetically critical interactions. Thus, the affinity of IL-10R2 for the IFN $\lambda 3$ / IFN $\lambda$ R1 complex (e.g., site- 2 + site-3) is $15 \mu \mathrm{M}$ (79), which is $\sim 15 \times$ lower than the affinity of IFNAR1 for most IFN subtypes $(26,27)$. While IFN $\lambda 3 /$ IFN $\lambda$ R1 represents the "high affinity" interaction in the complex, the measured $\mathrm{KD}$ of $850 \mathrm{nM}(79)$ is $~ 1$ $\log$ lower than the affinity of the weakest type-I IFN for IFNAR2 (e.g., IFN $\alpha 1, K D \sim 100 \mathrm{nM}$ ).

Due to the low affinity of the IFN $\lambda$ s for their receptors, the IFN $\lambda$ s are sensitive to the expression levels of their receptors on cells. In fact, a major distinction between type-I and type-III IFNs is the unique distribution of their receptors on different cell types $(81,82)$. Type-I IFNAR1 and IFNAR2 receptors are present on all nucleated cells, while IFN $\lambda \mathrm{R} 1$ expression is predominantly limited to epithelial cells, as mentioned for IL22R1 earlier $(22,70)$. Thus, IFN $\lambda$ signaling appears to be specialized for combating viral infections at epithelial barrier surfaces such as the lung, gut, and liver (83). This has most impressively been shown by demonstrating IFN $\lambda$, but not type-I IFN, is essential for controlling norovirus infection (84). Although gut epithelial cells in this study express type-I IFNARs, their expression is limited to the apical surface of the cells, and no IFNAR expression is observed on the basolateral surface. Thus, the selective signaling of IFN $\lambda$ in gut epithelial cells was only fully appreciated within the organization of the intact gut in animals. While IFN $\lambda$ activity appears "weak" in many cell-based assays, in vivo data suggests potent IFN $\lambda$ signaling in the context of tissues and organs. It should be noted that type-I IFNs, IFNe and IFNא, protect the female reproductive track $(85-87)$ and skin $(15,88)$, respectively. Notably, like the IFN $\lambda$ s, IFNe and IFNא exhibit "low" affinity for the type-I receptors, relative to most type-I IFNs (89).

\section{Insights From IFN $\lambda 1 /$ IFN $\lambda R 1$ and IFN $\lambda 3$ / IFN $\lambda$ R1 Binary Structures}

Both IFN $\lambda 1 /$ IFN $\lambda$ R 1 and IFN $\lambda 3 /$ IFN $\lambda$ R1 binary complex structures have been solved $(79,90)$. IFN $\lambda 1$ and IFN $\lambda 3$ adopt very similar structures, with a root-mean-square deviation (r.m.s.d.) of $0.6 \AA$. Similarly, IFN $\lambda$ R1 binding to either IFN $\lambda 1$ or IFN $\lambda 3$ exhibits an r.m.s.d. of $0.68 \AA$. Finally, the structure of unbound IL10R2 (91) and IL10R2 bound to IFN $\lambda 3$ exhibit an r.m.s.d. of $1.3 \AA$. The larger r.m.s.d. is due to changes in the conformation of the IL10R2 L5 binding loop upon contacting IFN $\lambda 3$. Despite this difference, the overall structures of bound and unbound IL10R2 are the same. These structural comparisons suggest all IFN $\lambda$ s assemble a signaling complex with the same overall architecture. Thus, IFN $\lambda$ biological potency is not regulated by the structure of the ternary complex, but by the affinity of each IFN $\lambda$ for the IFN $\lambda$ R 1 and IL10R 2 chains, and ultimately the stability of the complex.

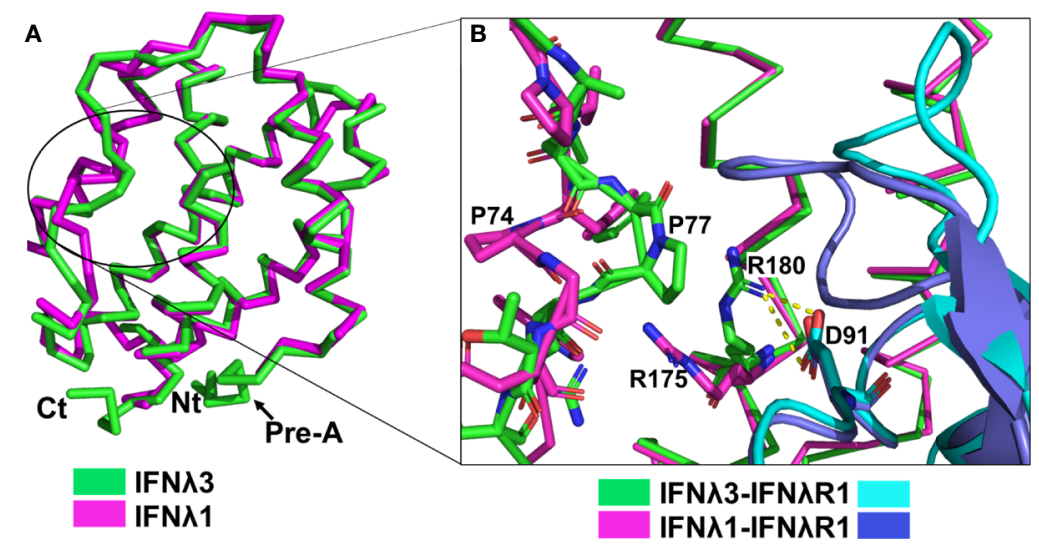

FIGURE 3 | Subtle structural changes between IFN $\lambda 1 /$ IFN $\lambda 3$ alter IFN $\lambda$ R1 Contacts. (A) Alpha carbon diagram of the superposition of IFN $\lambda 1$ and IFN $\lambda 3$. The location of structural differences in the B loop regions of IFN $\lambda 1$ and IFN $\lambda 3$, as discussed in the text, are circled. (B) Enlargement of the B loop "proline flip" observed in IFN $\lambda 1$ and IFN $\lambda 3$ structures and its influence on the conformation of Arg-180 IFN $\lambda 3$ (green), where it makes a salt bridge with IFN $\lambda$ R1 Asp-91. In contrast, IFN $\lambda 1$ Arg-175 (magenta) extends away from IFN $\lambda$ R1 Asp-91 towards the B loop. 
In vitro cell-based assays demonstrate IFN $\lambda 3$ exhibits twofold greater antiviral potency than IFN $\lambda 1$ (92). Although a detailed analysis of IFN $\lambda$ receptor binding affinity has not been completed, we expect the IFN $\lambda 3 /$ IFN $\lambda$ R1 complex should exhibit differences from the IFN $\lambda 1 /$ IFN $\lambda$ R 1 complex, consistent with a higher affinity interaction. Comparison of IFN $\lambda 1$ and IFN $\lambda 3$ structures (Figure $3 \mathbf{A}$ ) reveals the B loop regions of IFN $\lambda 1$ and IFN $\lambda 3$ exhibit different conformations, particularly Pro- $74^{\mathrm{IFN} \lambda 1} /$ Pro- $77^{\mathrm{IFN} \lambda 3}$ (Figure 3B). In IFN $\lambda 3$, Pro-77 moves in toward helix F, while in IFN $\lambda 1$ Pro-74 moves away from helix F. This "proline flip" alters the position of the conserved Arg-175 ${ }^{\mathrm{IFN} \lambda 1} / \mathrm{Arg}-180^{\mathrm{IFN} \lambda 3}$, located on helix F (Figure 3B). In IFN $\lambda 3$, the guanidino group of Arg-180 packs against Pro-77, which positions it for a bivalent salt bridge with IFN $\lambda$ R1 residue Asp-91. A series of IFN $\lambda 3$ alanine mutants were tested for antiviral activity and identified Phe-179 as the most important IFN $\lambda 3$ residue for inducing antiviral activity (19). Since IFN $\lambda 3$ Phe-179 is adjacent to Arg-180, it is likely that mutation of Phe-179 to an alanine disrupts the Arg- $180^{\mathrm{IFN} \lambda 3}$ / Asp-91 ${ }^{\text {IFN } \lambda \text { R1 }}$ salt bridge, which reduces IFN $\lambda$ R1 binding affinity and antiviral activity.

The "proline flip" observed between IFN $\lambda 1$ and IFN $\lambda 3$ (Figure 3B) may also provide mechanistic insight into the reduced biological activity of the IFN $\lambda 4$ single nucleotide polymorphism (SNP), rs117648444. Rs11768444 corresponds to IFN $\lambda 4$-Pro70Ser, which exhibits reduced antiviral activity, relative to wildtype IFN $\lambda 4(25,93)$. Understanding IFN $\lambda 4$ SNPs is important since several groups have mapped the major genetic determinant of hepatitis $\mathrm{C}$ virus (HCV) clearance, in response to treatment with IFN- $\alpha$ plus ribavirin, to the type-III IFN loci (9496). Ultimately, IFN $\lambda 4$ activity has been implicated as the causative agent of HCV clearance failure in patients that encode "active" IFN $\lambda 4$ protein, as opposed to inactive IFN $\lambda 4$ protein (25). Despite sharing $\sim 28 \%$ sequence identity with IFN $\lambda 3$, IFN $\lambda 4$ adopts the same $\alpha$-helical fold as other IFN $\lambda$ s and binds to IFN $\lambda$ R1 and IL10R2 (97). Amino acid sequence alignments show IFN $\lambda 4$ Pro-70 is identical to IFN $\lambda 3$ Pro-77, suggesting the IFN $\lambda 4$ Pro70Ser mutation impacts IFN $\lambda 4$ IFN $\lambda$ R1 interactions by altering the structure of IFN $\lambda 4$ Arg163, as described for Arg-180 in IFN $\lambda 3$ (Figure 3B).

IFN $\lambda 2$ has not been studied to the same extent as the other IFN $\lambda$ s, presumably because it was shown to exhibit $\sim 5-10 \times$ lower antiviral activity $(53,98)$. The IFN $\lambda 2$ amino acid sequence differs from IFN $\lambda 3$ by only 6 amino acids. Modeling the structure of IFN $\lambda 2$ based on the structure of IFN $\lambda 3$ suggests, R $28 \mathrm{H}$ occurs in a non-structured region at the N-terminus of the molecule, where it is not predicted to alter receptor binding. K70R and $\mathrm{R} 72 \mathrm{H}$ are located in the AB loop of IFN $\lambda 2$, but do not contact IFN $\lambda$ R1. Furthermore, an IFN $\lambda 3$ R72A mutant reduced IFN $\lambda 3$ anti-viral activity by only $30 \%$, suggesting these residue changes cannot explain the lower activity of IFN $\lambda 2$. Residues V92M and $\mathrm{H} 156 \mathrm{Y}$ are located on exposed surfaces of IFN $\lambda 2$ helices $\mathrm{C}$ and $\mathrm{E}$, respectively, which are located opposite the IFN $\lambda$ R1 and IL10R2 binding sites. Thus, if these amino acids were responsible for the lower activity of IFN $\lambda 2$, this would support the hypothesis of some groups that IFN $\lambda$ may bind to another, unidentified, receptor chain (83). Finally, L133F is located on helix D, where the sidechain is buried in the hydrophobic core of IFN $\lambda 2$. The L-to-F amino acid change cannot be incorporated into the hydrophobic core of the IFN $\lambda 3$ structure without distorting helices A, D, or F. This suggests L133F may be the main residue responsible for the reduced biological activity of IFN $\lambda 2$, relative to IFN $\lambda 3$.

\section{The Type-II IFN $\gamma /$ IFNGR1/IFNGR2 Complex}

The type-II IFN $\gamma$ receptor complex provides an important structure to further understand the type-I and type-III complexes (99). The unique intercalated dimer structure (6) of IFN $\gamma$ distinguishes it from the disulfide-linked monomeric type-I and type-III IFNs $(4,19,100)$. The IFN $\gamma$ dimer assembles a symmetric 1:2:2 IFNGR1/IFNGR2 heterodimeric complex (99, 101) (Figure 4), compared to the 1:1:1 heterodimeric complexes of the type-I and type-III IFNs (Figure 2). In the dimeric complex, the twofold-related C-termini of the IFNGR1/ IFNGR2 heterodimers are positioned $85 \AA$ apart from one another. As suggested from the analysis of the structurally related IL10 dimer (102), the dimeric IFN $\gamma$ positions IFNGR1 and IFNGR2 (Figure 4), and their respective ICDs, in an optimal dimeric arrangement to recruit inactive STAT1 dimers (103) for subsequent phosphorylation and activation of STAT1 homodimers (104). Disruption of the dimeric IFN $\gamma$ receptor complex architecture, using engineered monomeric IFN $\gamma$, which assembles $1 / 2$ of the dimeric IFN $\gamma /$ IFNG1/IFNGR2 (see Figure 2 vs. Figure 4), drastically reduced some IFN $\gamma$-induced biological activities $(7,8,99,102,105)$. Additional IFN $\gamma$ mutants confirmed the dimeric arrangement of IFNGR1, not IFNGR2, was essential for full STAT1 phosphorylation (99). In contrast to

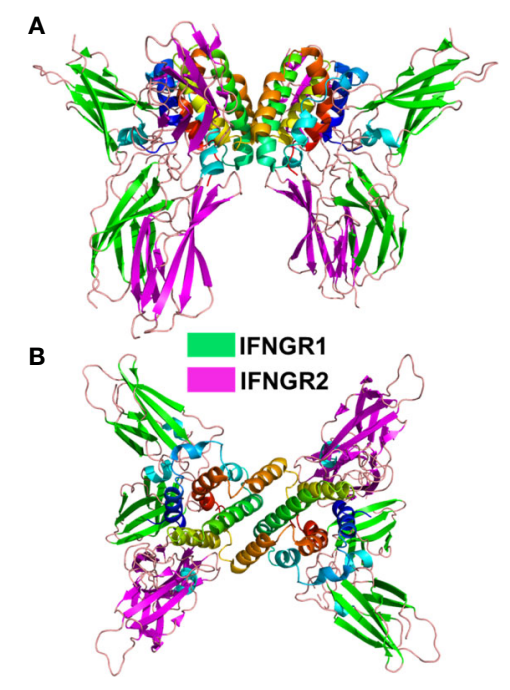

FIGURE 4 | Dimeric IFN $\gamma /$ IFNGR1/IFNGR2 Complex. Ribbon diagram of the 1:2:2 IFN $\gamma$ dimer/IFNGR1/IFNGR2 complex (pdbid = 6E3K). Two views of the complex are shown. The first is approximately perpendicular to the IFN $\gamma$ twofold axis (A) and the second is parallel to the twofold axis (B). 
STAT1, many additional pathways activated by IFN $\gamma$, including MAP kinase, PI3K, and CaMKII (106), appear not to be equally sensitive to IFN $\gamma$-mediated IFNGR1/IFNGR2 dimerization. Thus, at least on some cells, engineered IFN $\gamma$ monomers can induce the same levels of cell surface HLA-A as the WT IFN $\gamma$ dimer (99). Interestingly, it should be noted that neurons appear to naturally manipulate IFN $\gamma$ signaling outcomes by maintaining low STAT1 levels, which results in potent IFN $\gamma$-mediated activation of ERK1/2 (107). Overall, the dimeric architecture of the IFN $\gamma /$ IFNGR1/IFNGR2 complex is critical for inducing the full spectrum of IFN $\gamma$-mediated pleotropic activities (108), which includes macrophage activation $(109,110)$, tumor surveillance $(111,112)$, and protection from intracellular pathogens, including mycobacteria $(50,113)$.

Despite the larger dimeric assembly, within one IFN $\gamma$ subunit, IFNGR1 and IFNGR2 form similar site-1, site-2, and D2-D2 site3 interfaces, as previously described for the IFN $\lambda /$ IFN $\lambda$ R1/ IL10R2 complex (Figure 2B). Compared to IFN $\lambda /$ IFN $\lambda$ R1, the IFN $\gamma$ site- 1 interface is more extensive with major contacts between the AB loop and helix F of IFN $\gamma$ and IFNGR1 L2-L6 loops. The site- 2 IFN $\gamma /$ IFNGR2 interface is comprised almost exclusively of contacts with IFN $\gamma$ helix $\mathrm{D}$ and no contacts with helix A, the main contact region in the IFN $\lambda$ complex. Despite these differences, IFNGR2 still forms a D2-D2 site 3 interface with the IFNGR1, which positions the C-termini of the receptors $22 \AA$ apart at the cell surface prior to their entry into the membrane. Thus, assembly of the IFN $\gamma$ signaling complex is cooperative, requiring the formation of the IFN $\gamma /$ IFNGR1 binary complex first, followed by IFNGR2 binding to induce cell signaling.

\section{The Type-I IFN/IFNAR1/IFNAR2 Complex}

The type-I IFN receptor complex is distinct from both the type-II and type-III receptor complexes (Figure 2). The high affinity IFNAR2 chain adopts a two-domain D1/D2 receptor structure, as observed for IFN $\lambda$ R1 and IFNGR1 chains (Figure 2) (114). NMR and X-ray structures confirm IFNAR2 binds to an IFN site- 1 epitope that is comprised of residues on helix $A$, the $A B$ loop, and helix F, similar to the type-II and type-III IFNs (100, 115, 116). IFNAR2 makes extensive interactions with Arg-33 (IFN 22 numbering) in the AB loop of the IFNs. Arg-33, and the structurally adjacent Leu-30, account for approximately two thirds of the IFN $22 /$ IFNAR2 binding energy (29, 100, 117). Additional critical contacts occur with the IFNAR2 L3 and L4 binding loops, which contact helix F residues Met-148 and Arg149 (IFN 22 numbers) (117). Although we know that all 16 IFNs exhibit a variety of affinities for IFNAR2 $(26-28,89)$, the mechanisms that control IFNAR2 affinity for each IFN subtype remains incomplete. In general, it appears that subtle changes to residues around these energetically critical residues modulate IFN-subtype IFNAR2 affinity.

The type-I IFN low affinity receptor chain, IFNAR1, is completely unique relative to the other IFN and IL10 family cytokine receptors (Figure 2). IFNAR1 consists of four $\beta$ sandwich domains (D1-D4), similar to tandem D1/D2 receptors, where the $\mathrm{D} 4$ domain is the membrane proximal domain. The D2 and D3 domains of the receptor form an extensive interface with one another, while the D1 domain can undergo rigid body movements. Overall, IFNAR1 D1-D3 domains form an IFN-binding module, while the D4 domain is attached to D3 by a flexible linker that allows the D4 domain to adopt multiple conformations, even when bound to IFN (100, 118). Despite a unique structure, IFNAR1 loops at the ends of D1, D2 and D3 domains contact IFN helices C, D, and E, with the D1 domain "closing down" on helix E, like a hand grabbing a glass.

Based on the features described above, the binding of type-I IFNs by IFNAR1 represents a novel protein recognition paradigm. First, the IFNAR1-IFN contact surface, consisting of IFN helices C, D, and E, is larger than for the other IFN complexes. Second, the membrane proximal D4 domain of IFNAR1 does not form a site 3 interface, at least not a stable interface, with the D2 domain of IFNAR2. This suggests that by increasing the size of the IFNAR1-IFN site-2 interface (see Figure 2C), using novel D1/helix E interactions, the type-I IFN complex no longer requires a site- 3 interface. Thus, for the type-I IFN complex, there is no structure-based cooperativity enforced by a D2-D4 site-3 interaction. Rather, receptor complex assembly and stability is controlled completely by IFN-IFNAR2 and IFN-IFNAR1 affinities. While it is possible that free IFNs, and IFNs bound to IFNAR2, could exhibit different affinities for IFNAR1, resulting in an affinity-based cooperative binding mechanism, this has not been demonstrated experimentally.

The mechanistic role of the IFNAR1 D4 domain in type-I IFN receptor activation remains unclear since the $\mathrm{D} 4$ domain was not observed in crystal structures of the IFN/IFNAR1/IFNAR2 complex (Figure 5A). To identify possible location/s of the IFNAR1 D4 domain, the IFN $\lambda 3 /$ IFN $\lambda$ R1/IL10R2 complex was superimposed onto the IFN $\omega /$ IFNAR1/IFNAR2 complex (Figure 5B). In this model, the D1 domain of IL10R2 overlaps with the IFNAR1 D3 domain and the putative location of the IFNAR1 D4 domain, represented by the IL10R2 D2 domain, is adjacent to the IFNAR2 D2 domain creating a D2-D4 site-3 interface, as observed in type-II and type-III complexes (Figure 2). A second possible position of the $\mathrm{D} 4$ domain is provided by the structure of the murine IFN $\beta /$ IFNAR1 binary complex (119), where all four domains of IFNAR1 were observed. Superposition of the murine IFN $\beta /$ IFNAR1 complex on the IFN/IFNAR1/ IFNAR2 human complex places the C-terminal ends of IFNAR2 D2 and IFNAR1 D4 51 contrast to $30 \AA$ and $22 \AA$ for the IFN $\lambda$ and IFN $\gamma$ complexes, respectively. These models lead to two possible conclusions. First, type-I IFNs assemble a novel "open" complex with the C-terminal ends of IFNAR1 and IFNAR2 separated by $\sim 50 \AA$. Second, the "open" conformation is an inactive complex, which must "close" to form a D2/D4 site-3 interface to induce IFN activity. Our analysis suggests that IFN binding to IFNAR2 and IFNAR1 promotes transient IFNAR2-D2/IFNAR1-D4 interactions. Thus, the stability of the IFN/IFNAR1/IFNAR2 interaction would control the number of transient "open"/ "closed" D2-D4 site-3 binding events, which could influence signaling strength. Thus, the stability of the IFN/IFNAR2 and 

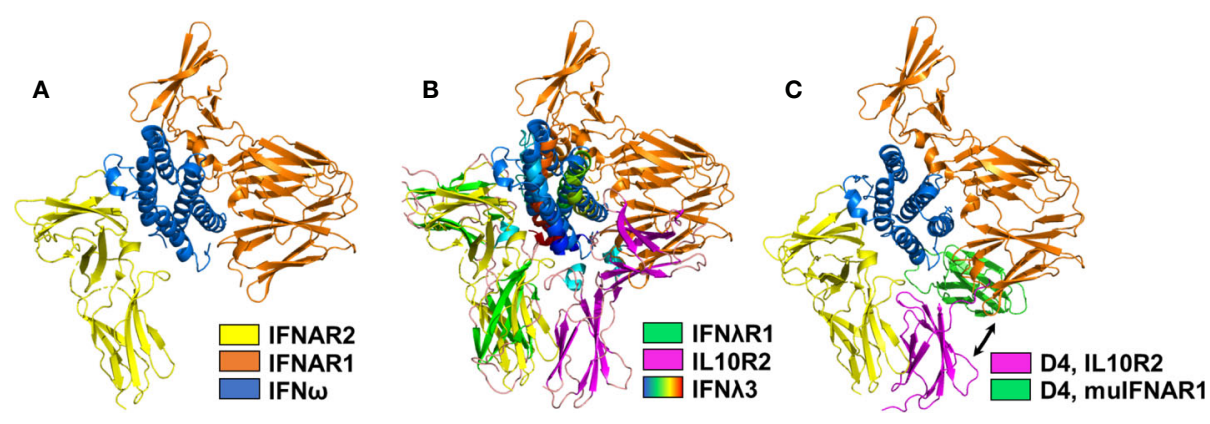

FIGURE 5 | Structural Models of the IFNAR1 D4 Domain. (A) Ribbon diagram of the type-I IFN (IFN $\omega$, blue)/IFNAR1 (orange)/IFNAR2 (yellow) complex structure (pdbid = 3SE4), which lacks the IFNAR1 D4 domain. (B) Superposition of the IFN $\lambda 3$ (rainbow)/IFN $\lambda$ R1 (green)/IL10R2 (magenta) ternary complex on the IFN/IFNAR1/ IFNAR2 structure positions the IL10R2 D2 domain (magenta), such that it could represent the transient location of the IFNAR1 D4 domain forming an IFNAR2 D2IFNAR1 D4 stem interaction. (C) A second possible location of the human IFNAR1 D4 domain is shown by superimposing the murine IFNB/IFNAR1 complex (pdbid $=3 \mathrm{WCY}$ ) on the IFN/IFNAR1/IFNAR2 complex. The position of the modeled D4 domain (green), derived from the murine IFN $\beta /$ IFNAR1 structure is shown in green, and the location of the IFNAR1 D4 domain obtained from superimposing the IFN $\lambda$ receptor complex is shown in magenta. Since the human IFNAR1 D4 domain does not form a stable D2-D4 interaction with IFNAR2, D4 may transition between green and magenta conformations to induce biological activity. The exact role of the D4 domain in IFN signal transduction remains unknown.

IFN/IFNAR1 interactions would regulate signaling, as has been previously described (120).

Despite structures that reveal extracellular IFN-receptor recognition and assembly mechanisms, there remain questions about IFN-mediated signal transducing events that initiate and sustain cellular activation. For example, it remains unclear how all 16 IFNs, that exhibit a spectrum of affinities for the IFNARs (weak/strong), can all activate a subset of genes associated with antiviral activity on all cells, while additional cellular functions of the IFNs, one such readout being anti-proliferative activity, correlates with IFN-IFNAR affinity (121). These two distinct cellular readouts, labeled as robust and tunable activation (121), might be explained by an IFNAR1/2 pre-association model (122) and an IFN-mediated IFNAR $1 / 2$ heterodimerization model (123), respectively. The IFNAR pre-association could account for rapid IFN-mediated activation of antiviral gene expression, while IFN-mediated IFNAR dimerization could account for tunable gene expression. The implication of the pre-association model is that the IFNs induce a structural change in the IFNARs that activate JAK1/TYK2 and induce rapid anti-viral gene expression, while the dimerization model relies solely on IFNmediated dimerization of the IFNARs to activate JAK1/TYK2 and subsequently induce IFN-mediated gene expression. Technical issues, specifically analysis of artificially high IFNAR expression levels, have been suggested to be responsible for the observation of pre-associated IFNARs (123). Unfortunately, the investigators criticizing the pre-association model did not confirm that overexpression of the IFNARs leads to IFNAR1/2 interactions. Nonetheless, the cortical actin cellular meshwork and/or lipid rafts could provide a suitable mechanism to "concentrate" IFNARs for rapid induction of robust antiviral genes by all IFNs, while still allowing tunable activities that are dependent on IFN-IFNAR affinities (124). Overall, the data suggest that the major mechanism regulating IFN activation is IFN-mediated IFNAR1/2 heterodimerization, although some recent data suggests IFN-induced IFNAR conformational changes may also regulate IFN activity (125).

\section{The Murine Type-I IFN Family Is Distinct From Human Type-I IFNs}

The murine IFN $\beta /$ IFNAR1 binary complex structure provides an important datapoint in the proposed model of human type-I IFN signaling. However, my lab and others have previously noted the "uniqueness" of type-I IFN families in different animals $(10,126-$ 129). For example, the murine IFN system consists of 14 IFNos (note that murine and human IFN $\alpha$ subtype designations have no bearing on their interspecies sequence and/or functional similarities), as well as IFN $\beta$, IFNe, IFNא, limitin (130), but do not encode an IFNW (126). Thus, it is necessary to ask if the murine IFNs and receptor proteins, as well as their biological outcomes, can be extrapolated to humans. From a structural biology perspective, the overall folds of murine (62) and human (5) IFN $\beta$, which share $47 \%$ sequence identity, are almost identical (Figure 6A). The extracellular regions of human and murine IFNAR 1 share $49 \%$ amino acid sequence identity and the structures of D1-D3 domains of murine and human IFNAR1s are also almost identical (119). These findings suggest the overall model proposed for the missing D4 domain in the human IFN/ IFNAR2/IFNAR1 complex is plausible (Figure 5).

Despite similar overall receptor complex structures, the receptor binding properties of murine and human IFN $\beta$ are distinct. Human IFN $\beta$ binds to IFNAR1 and IFNAR2 with $\sim 30 \mathrm{nM}$ and $\sim 0.1 \mathrm{nM} K \mathrm{KD}$ values, respectively (28). However, in the mouse, IFN $\beta$ receptor affinities are "flipped" such that the IFN $\beta$-IFNAR1 forms the high affinity interaction $(K \mathrm{D} \sim 10 \mathrm{nM})$ and the IFN $\beta$-IFNAR2 forms the low affinity interaction (KD $\sim 1.7 \mu \mathrm{M})$ (86). Structural comparisons of human and murine IFN $\beta$ reveal the $A B$ loop of murine IFN $\beta$, which forms a major part of the IFNAR2 site-1 binding site, exhibits a distinct structure compared to human IFN $\beta$ (Figure 6). In human 


\section{A}

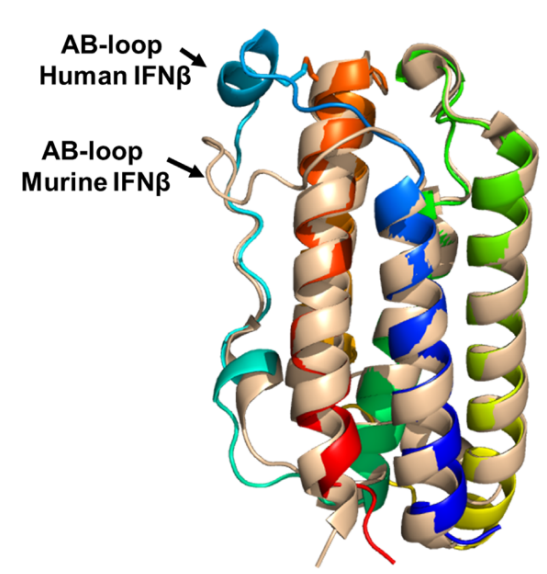

B

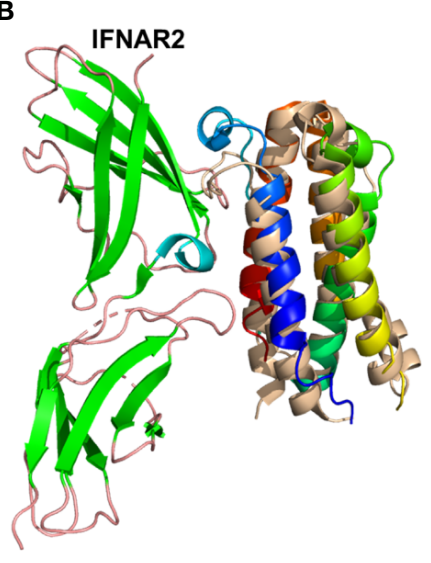

FIGURE 6 | Structural Comparison of human and murine IFN $\beta$. (A) Structural superposition of human IFN $\beta$ (colored as in Figure 1, pdbid = 1AU1) and murine IFN $\beta$ (wheat, pdbid = 1WU3), highlighting their distinct AB loop structures. (B) Structural superposition of murine and human IFN $\beta$ onto IFN $\alpha 2$ from the human IFN $\alpha 2 / I F N A R 2$ crystal structure. The resulting structural model results in steric clashes between the murine IFN $\beta$ AB loop and IFNAR2 binding loops, but not for the human IFN $\beta /$ IFNAR2 model. This structural analysis provides an explanation for the low affinity of the murine IFN $\beta /$ IFNAR2 interaction, compared to the high affinity human IFN $\beta / I F N A R 2$ interaction.

IFN $\beta$, the AB-loop arches toward the N-terminal end of helix-F, "over" helix F itself, where the loop connects to helix F by a disulfide bond. In contrast, the murine IFN $\beta$ AB-loop wraps "across" helix F where it would disrupt high affinity IFNAR2 interactions, as observed in the human IFN $\alpha /$ IFNAR2 crystal structure (Figure 6B). Interestingly, sequence alignments reveal the murine IFNAR2 receptor binding loops that contact the $A B$ loop region of murine IFN $\beta$ are the same length as human IFNAR2. In addition, murine IFN $\alpha$ s bind with high affinity $(K D$ $\sim 1 \mathrm{nM}$ ) to murine IFNAR2 (86). Thus, it is likely murine IFNAR2 receptor binding loops do not change their lengths, or grossly change their conformations, to accommodate the distinct murine IFN $\beta$ AB loop structure. Together, these structural observations provide an explanation for the low affinity of the murine IFN $\beta$ / IFNAR2 interaction, compared to the human IFN $\beta$-IFNAR2 interaction. While this structural analysis is satisfying with respect to murine and human IFN $\beta$, it highlights the many distinct properties of the murine IFNs, from structure to mechanism to in vivo outcomes, remain uncharacterized.

\section{Moving Forward}

This review has focused on fundamental structural features of the three human IFN families, highlighting similar and unique features of each receptor complex. The ultimate goal of structural studies is to define mechanisms that can be used to discover optimal IFN therapeutics that harness the antiviral activity of the IFNs to improve human health (131). The importance of this goal is highlighted by the SARS-CoV-2 pandemic that is ravaging our society $(72,132-134)$. Based on the critical role that IFN - IFN receptor affinity plays in varying IFN activity $(26,120,135)$, type-I and type-III IFNs with increased receptor affinity have been designed, yet they have not advanced into the clinic (79, 136, 137). Presumably because we still do not know the optimal design principles to create an optimal IFN therapeutic. Given that humans produce 20 different type-I/III IFNs in response to pathogens, the design may not be simple and might require the synergistic actions of both type-I and type-III IFNs. For example, type-I IFN $\beta$ and type-III IFN $\lambda 3$ induced distinct anti-viral gene expression profiles with distinct kinetics on human hepatocytes (138). Specifically, high affinity IFN $\beta$ induced potent antiviral protection almost immediately $(\sim 2 \mathrm{~h})$ after addition to cells that waned after $\sim 48 \mathrm{~h}$. In contrast, IFN $\lambda 3$ antiviral activity was not observed until $\sim 12 \mathrm{~h}$ after treatment, but was sustained for at least $72 \mathrm{~h}$ post-treatment (138). These data highlight the interplay of distinct receptor affinities and negative feedback mechanisms (139, 140), which synergistically control IFN-mediated antiviral signaling. Notably, type-III IFN signaling has been shown to be resistant to USP18mediated negative feedback regulation, which potently regulates type-I IFN signaling (141). USP18 is induced by type-I and type-III IFNs, but specifically binds to the ICD of IFNAR2 and disrupts IFN $\alpha$-mediated IFNAR1/IFNAR2 complex formation. These studies demonstrate that the anti-viral signaling cascade induced by type-I and type-III IFNs is very similar, yet multiple mechanisms can tailor the response for optimal functional outcomes, which include eliminating the virus and protecting the host. These studies, and more like them, are providing new design principles to further our quest for safe and efficacious IFNs with broad-spectrum antiviral activity.

\section{AUTHOR CONTRIBUTIONS}

MRW performed literature searches, made figures, and wrote the manuscript.

\section{FUNDING}

This manuscript was funded in part by NIH grant R01 AI143554. 


\section{REFERENCES}

1. Isaacs A, Lindenmann J. Virus interference. I. The interferon. Proc R Soc Lond B Biol Sci (1957) 147(927):258-67. doi: 10.1098/rspb.1957.0048

2. Wheelock EF. Interferon-like virus-inhibitor induced in human leukocytes by phytohemagglutinin. Science (New York NY) (1965) 149(3681):310-1. doi: 10.1126/science.149.3681.310

3. Stewart WE. 2nd. Interferon nomenclature recommendations. J Infect Dis (1980) 142(4):643. doi: 10.1093/infdis/142.4.643

4. Radhakrishnan R, Walter LJ, Hruza A, Reichert P, Trotta PP, Nagabhushan TL, et al. Zinc mediated dimer of human interferon-alpha $2 \mathrm{~b}$ revealed by Xray crystallography. Structure (1996) 4(12):1453-63. doi: 10.1016/S09692126(96)00152-9

5. Karpusas M, Nolte M, Benton CB, Meier W, Lipscomb WN, Goelz S. The crystal structure of human interferon beta at 2.2-A resolution. Proc Natl Acad Sci U S A (1997) 94(22):11813-8. doi: 10.1073/pnas.94.22.11813

6. Ealick SE, Cook WJ, Vijay-Kumar S, Carson M, Nagabhushan TL, Trotta $\mathrm{PP}$, et al. Three-dimensional structure of recombinant human interferongamma. Science (New York NY) (1991) 252(5006):698-702. doi: 10.1126/ science. 1902591

7. Landar A, Curry B, Parker MH, DiGiacomo R, Indelicato SR, Nagabhushan TL, et al. Design, characterization, and structure of a biologically active single-chain mutant of human IFN-gamma. J Mol Biol (2000) 299(1):16979. doi: $10.1006 /$ jmbi.2000.3734

8. Randal M, Kossiakoff AA. The structure and activity of a monomeric interferon-gamma:alpha-chain receptor signaling complex. Struct (Camb) (2001) 9(2):155-63. doi: 10.1016/S0969-2126(01)00567-6

9. Díaz MO, Pomykala HM, Bohlander SK, Maltepe E, Malik K, Brownstein B, et al. Structure of the human type-I interferon gene cluster determined from a YAC clone contig. Genomics (1994) 22(3):540-52. doi: 10.1006/ geno.1994.1427

10. Pestka S. The human interferon-alpha species and hybrid proteins. Semin Oncol (1997) 24(3 Suppl 9):S9-4-S9-17.

11. Pestka S. The interferons: 50 years after their discovery, there is much more to learn. J Biol Chem (2007) 282(28):20047-51. doi: 10.1074/jbc.R700004200

12. Pestka S, Krause CD, Sarkar D, Walter MR, Shi Y, Fisher PB. Interleukin-10 and related cytokines and receptors. Annu Rev Immunol (2004) 22:929-79. doi: 10.1146/annurev.immunol.22.012703.104622

13. Pestka S, Krause CD, Walter MR. Interferons, interferon-like cytokines, and their receptors. Immunol Rev (2004) 202:8-32. doi: 10.1111/j.01052896.2004.00204.x

14. Hardy MP, Owczarek CM, Jermiin LS, Ejdeback M, Hertzog PJ. Characterization of the type I interferon locus and identification of novel genes. Genomics (2004) 84(2):331-45. doi: 10.1016/j.ygeno.2004.03.003

15. LaFleur DW, Nardelli B, Tsareva T, Mather D, Feng P, Semenuk M, et al. Interferon-kappa, a novel type I interferon expressed in human keratinocytes. J Biol Chem (2001) 276(43):39765-71. doi: 10.1074/ jbc.M102502200

16. Hauptmann R, Swetly P. A novel class of human type I interferons. Nucleic Acids Res (1985) 13(13):4739-49. doi: 10.1093/nar/13.13.4739

17. Sheppard P, Kindsvogel W, Xu W, Henderson K, Schlutsmeyer S, Whitmore TE, et al. IL-28, IL-29 and their class II cytokine receptor IL-28R. Nat Immunol (2003) 4(1):63-8. doi: 10.1038/ni873

18. Kotenko SV, Gallagher G, Baurin VV, Lewis-Antes A, Shen M, Shah NK, et al. IFN-lambdas mediate antiviral protection through a distinct class II cytokine receptor complex. Nat Immunol (2003) 4(1):69-77. doi: 10.1038/ ni875

19. Gad HH, Dellgren C, Hamming OJ, Vends S, Paludan SR, Hartmann R. Interferon-lambda is functionally an interferon but structurally related to the interleukin-10 family. J Biol Chem (2009) 284(31):20869-75. doi: 10.1074/ jbc.M109.002923

20. Walter MR. Strucure of interleukin-10/interleukin-10R1 complex: a paradigm for class 2 cytokine activation. Immunol Res (2002) 26(1-3): 303-8. doi: 10.1385/IR:26:1-3:303

21. Walter MR. Structural analysis of IL-10 and Type I interferon family members and their complexes with receptor. Adv Protein Chem (2004) 68:171-223. doi: 10.1016/S0065-3233(04)68006-5
22. Ouyang W, Rutz S, Crellin NK, Valdez PA, Hymowitz SG. Regulation and functions of the IL-10 family of cytokines in inflammation and disease. Annu Rev Immunol (2011) 29:71-109. doi: 10.1146/annurev-immunol-031210101312

23. Xu T, Logsdon NJ, Walter MR. Structure of insect-cell-derived IL-22. Acta Crystallogr D Biol Crystallogr (2005) 61(Pt 7):942-50. doi: 10.1107/ S0907444905009601

24. Nagem RA, Colau D, Dumoutier L, Renauld JC, Ogata C, Polikarpov I. Crystal structure of recombinant human interleukin-22. Struct (Camb) (2002) 10(8):1051-62. doi: 10.1016/S0969-2126(02)00797-9

25. Prokunina-Olsson L, Muchmore B, Tang W, Pfeiffer RM, Park H, Dickensheets $\mathrm{H}$, et al. A variant upstream of IFNL3 (IL28B) creating a new interferon gene IFNL4 is associated with impaired clearance of hepatitis C virus. Nat Genet (2013) 45(2):164-71. doi: 10.1038/ng.2521

26. Lavoie TB, Kalie E, Crisafulli-Cabatu S, Abramovich R, DiGioia G, Moolchan K, et al. Binding and activity of all human alpha interferon subtypes. Cytokine (2011) 56(2):282-9. doi: 10.1016/j.cyto.2011.07.019

27. Deshpande A, Putcha BD, Kuruganti S, Walter MR. Kinetic analysis of cytokine-mediated receptor assembly using engineered FC heterodimers. Protein Sci (2013) 22(8):1100-8. doi: 10.1002/pro.2285

28. Jaks E, Gavutis M, Uze G, Martal J, Piehler J. Differential receptor subunit affinities of type I interferons govern differential signal activation. J Mol Biol (2007) 366(2):525-39. doi: 10.1016/j.jmb.2006.11.053

29. Piehler J, Schreiber G. Biophysical analysis of the interaction of human ifnar2 expressed in E. coli with IFNalpha2. J Mol Biol (1999) 289(1):57-67. doi: 10.1006/jmbi.1999.2726

30. Roisman LC, Jaitin DA, Baker DP, Schreiber G. Mutational analysis of the IFNAR1 binding site on IFNalpha2 reveals the architecture of a weak ligandreceptor binding-site. J Mol Biol (2005) 353(2):271-81. doi: 10.1016/ j.jmb.2005.08.042

31. Donnelly RP, Sheikh F, Dickensheets H, Savan R, Young HA, Walter MR. Interleukin-26: an IL-10-related cytokine produced by Th17 cells. Cytokine Growth Factor Rev (2010) 21(5):393-401. doi: 10.1016/j.cytogfr.2010.09.001

32. Donnelly RP, Sheikh F, Kotenko SV, Dickensheets H. The expanded family of class II cytokines that share the IL-10 receptor-2 (IL-10R2) chain. J Leukoc Biol (2004) 76(2):314-21. doi: 10.1189/jlb.0204117

33. Fickenscher H, Hor S, Kupers H, Knappe A, Wittmann S, Sticht H. The interleukin-10 family of cytokines. Trends Immunol (2002) 23(2):89-96. doi: 10.1016/S1471-4906(01)02149-4

34. Briscoe J, Guschin D, Rogers NC, Watling D, Muller M, Horn F, et al. JAKs, STATs and signal transduction in response to the interferons and other cytokines. Philos Trans R Soc Lond B Biol Sci (1996) 351(1336):167-71. doi: 10.1146/annurev.immunol.22.012703.104622

35. Ferrao R, Lupardus PJ. The Janus Kinase (JAK) FERM and SH2 Domains: Bringing Specificity to JAK-Receptor Interactions. Front Endocrinol (Lausanne) (2017) 8:71. doi: 10.3389/fendo.2017.00071

36. Kerr IM, Costa-Pereira AP, Lillemeier BF, Strobl B. Of JAKs, STATs, blind watchmakers, jeeps and trains. FEBS Lett (2003) 546(1):1-5. doi: 10.3389/ fendo.2017.00071

37. O'Shea JJ, Schwartz DM, Villarino AV, Gadina M, McInnes IB, Laurence A. The JAK-STAT pathway: impact on human disease and therapeutic intervention. Annu Rev Med (2015) 66:311-28. doi: 10.1146/annurevmed-051113-024537

38. O'Shea JJ, Visconti R, Cheng TP, Gadina M. Jaks and stats as therapeutic targets. Ann Rheum Dis (2000) 59(Suppl 1):i115-8. doi: 10.1146/annurevmed-051113-024537

39. Farrar MA, Schreiber RD. The molecular cell biology of interferon-gamma and its receptor. Annu Rev Immunol (1993) 11:571-611. doi: 10.1146/ annurev.iy.11.040193.003035

40. Borden EC, Sen GC, Uze G, Silverman RH, Ransohoff RM, Foster GR, et al. Interferons at age 50: past, current and future impact on biomedicine. Nat Rev Drug Discov (2007) 6(12):975-90. doi: 10.1038/nrd2422

41. Platanias LC. Mechanisms of type-I- and type-II-interferon-mediated signalling. Nat Rev Immunol (2005) 5(5):375-86. doi: 10.1038/nri1604

42. Samuel CE. Antiviral actions of interferons. Clin Microbiol Rev (2001) 14 (4):778-809. doi: 10.1128/CMR.14.4.778-809.2001

43. Graham MB, Dalton DK, Giltinan D, Braciale VL, Stewart TA, Braciale TJ. Response to influenza infection in mice with a targeted disruption in the 
interferon gamma gene. J Exp Med (1993) 178(5):1725-32. doi: 10.1084/ jem.178.5.1725

44. Huang S, Hendriks W, Althage A, Hemmi S, Bluethmann H, Kamijo R, et al. Immune response in mice that lack the interferon-gamma receptor. Science (New York NY) (1993) 259(5102):1742-5. doi: 10.1126/science.8456301

45. Wu J, Chen ZJ. Innate Immune Sensing and Signaling of Cytosolic Nucleic Acids. Annu Rev Immunol (2014) 32(1):461-88. doi: 10.1146/annurevimmunol-032713-120156

46. Chow KT, Gale MJr., Loo YM. RIG-I and Other RNA Sensors in Antiviral Immunity. Annu Rev Immunol (2018) 36:667-94. doi: 10.1146/annurevimmunol-042617-053309

47. Severa M, Fitzgerald KA. TLR-mediated activation of type I IFN during antiviral immune responses: fighting the battle to win the war. Curr Topics Microbiol Immunol (2007) 316:167-92. doi: 10.1007/978-3-540-71329-6_9

48. Park A, Iwasaki A. Type I and Type III Interferons - Induction, Signaling, Evasion, and Application to Combat COVID-19. Cell host Microbe (2020) 27 (6):870-8. doi: 10.1016/j.chom.2020.05.008

49. Bach EA, Aguet M, Schreiber RD. The IFN gamma receptor: a paradigm for cytokine receptor signaling. Annu Rev Immunol (1997) 15:563-91. doi: 10.1146/annurev.immunol.15.1.563

50. Sologuren I, Boisson-Dupuis S, Pestano J, Vincent QB, Fernandez-Perez L, Chapgier A, et al. Partial recessive IFN-gammaR1 deficiency: genetic, immunological and clinical features of 14 patients from 11 kindreds. Hum Mol Genet (2011) 20(8):1509-23. doi: 10.1093/hmg/ddr029

51. Hernandez N, Bucciol G, Moens L, Le Pen J, Shahrooei M, Goudouris E, et al. Inherited IFNAR1 deficiency in otherwise healthy patients with adverse reaction to measles and yellow fever live vaccines. J Exp Med (2019) 216 (9):2057-70. doi: 10.1084/jem.20182295

52. Pöyhönen L, Bustamante J, Casanova J-L, Jouanguy E, Zhang Q. LifeThreatening Infections Due to Live-Attenuated Vaccines: Early Manifestations of Inborn Errors of Immunity. J Clin Immunol (2019) 39 (4):376-90. doi: 10.1007/s10875-019-00642-3

53. Diegelmann J, Beigel F, Zitzmann K, Kaul A, Goke B, Auernhammer CJ, et al. Comparative analysis of the lambda-interferons IL-28A and IL-29 regarding their transcriptome and their antiviral properties against hepatitis C virus. PLoS One (2010) 5(12):e15200. doi: 10.1371/journal.pone.0015200

54. Zhou Z, Hamming OJ, Ank N, Paludan SR, Nielsen AL, Hartmann R. Type III interferon (IFN) induces a type I IFN-like response in a restricted subset of cells through signaling pathways involving both the Jak-STAT pathway and the mitogen-activated protein kinases. J Virol (2007) 81(14):7749-58. doi: 10.1128/JVI.02438-06

55. Smeekens SP, Ng A, Kumar V, Johnson MD, Plantinga TS, van Diemen C, et al. Functional genomics identifies type I interferon pathway as central for host defense against Candida albicans. Nat Commun (2013) 4:1342. doi: $10.1038 /$ ncomms 2343

56. Abt MC, Osborne LC, Monticelli LA, Doering TA, Alenghat T, Sonnenberg GF, et al. Commensal bacteria calibrate the activation threshold of innate antiviral immunity. Immunity (2012) 37(1):158-70. doi: 10.1016/ j.immuni.2012.04.011

57. Li S, Rouphael N, Duraisingham S, Romero-Steiner S, Presnell S, Davis C, et al. Molecular signatures of antibody responses derived from a systems biology study of five human vaccines. Nat Immunol (2014) 15(2):195-204. doi: $10.1038 /$ ni.2789

58. Wu JQ, Dwyer DE, Dyer WB, Yang YH, Wang B, Saksena NK. Transcriptional profiles in CD8 $\mathrm{T}$ cells from HIV+ progressors on HAART are characterized by coordinated up-regulation of oxidative phosphorylation enzymes and interferon responses. Virology (2008) 380 (1):124-35. doi: 10.1016/j.virol.2008.06.039

59. Klaus W, Gsell B, Labhardt AM, Wipf B, Senn H. The three-dimensional high resolution structure of human interferon alpha- 2 a determined by heteronuclear NMR spectroscopy in solution. J Mol Biol (1997) 274 (4):661-75. doi: 10.1006/jmbi.1997.1396

60. Radhakrishnan R, Walter LJ, Subramaniam PS, Johnson HM, Walter MR. Crystal structure of ovine interferon-tau at $2.1 \mathrm{~A}$ resolution. J Mol Biol (1999) 286(1):151-62. doi: 10.1006/jmbi.1998.2480

61. Walter MR. Three-dimensional models of interferon-alpha subtypes IFNcon1, IFN-alpha8, andIFN-alpha1 derived from the crystal structure of IFNalpha2b. Semin Oncol (1997) 24(3 Suppl 9):S9-52-S9-62.
62. Senda T, Saitoh S, Mitsui Y. Refined crystal structure of recombinant murine interferon-beta at 2.15 A resolution. J Mol Biol (1995) 253(1):187-207. doi: 10.1006/jmbi.1995.0544

63. Ouyang S, Gong B, Li JZ, Zhao LX, Wu W, Zhang FS, et al. Structural insights into a human anti-IFN antibody exerting therapeutic potential for systemic lupus erythematosus. J Mol Med (Berl) (2012) 90(7):837-46. doi: 10.1007/s00109-012-0866-3

64. Gad HH, Hamming OJ, Hartmann R. The structure of human interferon lambda and what it has taught us. J Interferon Cytokine Res (2010) 30 (8):565-71. doi: 10.1089/jir.2010.0062

65. Kotenko SV, Langer JA. Full house: 12 receptors for 27 cytokines. Int Immunopharmacol (2004) 4(5):593-608. doi: 10.1016/j.intimp.2004.01.003

66. Trivella DB, Ferreira-Junior JR, Dumoutier L, Renauld JC, Polikarpov I. Structure and function of interleukin-22 and other members of the interleukin-10 family. Cell Mol Life Sci (2010) 67(17):2909-35. doi: 10.1007/s00018-010-0380-0

67. Boniface K, Guignouard E, Pedretti N, Garcia M, Delwail A, Bernard FX, et al. A role for T cell-derived interleukin 22 in psoriatic skin inflammation. Clin Exp Immunol (2007) 150(3):407-15. doi: 10.1111/j.13652249.2007.03511.x

68. Brand S, Beigel F, Olszak T, Zitzmann K, Eichhorst ST, Otte JM, et al. IL-22 is increased in active Crohn's disease and promotes proinflammatory gene expression and intestinal epithelial cell migration. Am J Physiol Gastrointest Liver Physiol (2006) 290(4):G827-38. doi: 10.1152/ajpgi.00513.2005

69. Wolk K, Kunz S, Witte E, Friedrich M, Asadullah K, Sabat R. IL-22 increases the innate immunity of tissues. Immunity (2004) 21(2):241-54. doi: 10.1016/ j.immuni.2004.07.007

70. Zheng Y, Valdez PA, Danilenko DM, Hu Y, Sa SM, Gong Q, et al. Interleukin-22 mediates early host defense against attaching and effacing bacterial pathogens. Nat Med (2008) 14(3):282-9. doi: 10.1038/nm1720

71. Lazear HM, Schoggins JW, Diamond MS. Shared and Distinct Functions of Type I and Type III Interferons. Immunity (2019) 50(4):907-23. doi: 10.1016/j.immuni.2019.03.025

72. Prokunina-Olsson L, Alphonse N, Dickenson RE, Durbin JE, Glenn JS, Hartmann R, et al. COVID-19 and emerging viral infections: The case for interferon lambda. J Exp Med (2020) 217(5):1-4. doi: 10.1084/jem.20200653

73. Major J, Crotta S, Llorian M, McCabe TM, Gad HH, Priestnall SL, et al. Type I and III interferons disrupt lung epithelial repair during recovery from viral infection. Sci (N Y NY) (2020) 369(6504):712-7. doi: 10.1126/ science.abc2061

74. Broggi A, Ghosh S, Sposito B, Spreafico R, Balzarini F, Lo Cascio A, et al. Type III interferons disrupt the lung epithelial barrier upon viral recognition. Science(New York NY) (2020) 369(6504):706-12. doi: 10.1126/ science.abc3545

75. Grajales-Reyes GE, Colonna M. Interferon responses in viral pneumonias. Sci (N Y NY) (2020) 369(6504):626-7. doi: 10.1126/science.abd2208

76. Walter MR, Nagabhushan TL. Crystal structure of interleukin 10 reveals an interferon gamma-like fold. Biochemistry (1995) 34(38):12118-25. doi: 10.1021/bi00038a004

77. Zdanov A, Schalk-Hihi C, Gustchina A, Tsang M, Weatherbee J, Wlodawer A. Crystal structure of interleukin-10 reveals the functional dimer with an unexpected topological similarity to interferon gamma. Structure (1995) 3 (6):591-601. doi: 10.1016/S0969-2126(01)00193-9

78. Kotenko SV. The family of IL-10-related cytokines and their receptors: related, but to what extent? Cytokine Growth Factor Rev (2002) 13(3):22340. doi: 10.1016/S1359-6101(02)00012-6

79. Mendoza JL, Schneider WM, Hoffmann HH, Vercauteren K, Jude KM, Xiong A, et al. The IFN- $\lambda$-IFN- $\lambda$ R1-IL-10R $\beta$ Complex Reveals Structural Features Underlying Type III IFN Functional Plasticity. Immunity (2017) 46 (3):379-92. doi: 10.1016/j.immuni.2017.02.017

80. Jones BC, Logsdon NJ, Walter MR. Structure of IL-22 bound to its highaffinity IL-22R1 chain. Structure (2008) 16(9):1333-44. doi: 10.1016/ j.str.2008.06.005

81. Sommereyns C, Paul S, Staeheli P, Michiels T. IFN-lambda (IFN-lambda) is expressed in a tissue-dependent fashion and primarily acts on epithelial cells in vivo. PLoS Pathog (2008) 4(3):e1000017. doi: 10.1371/journal.ppat.1000017

82. Mordstein M, Neugebauer E, Ditt V, Jessen B, Rieger T, Falcone V, et al. Lambda interferon renders epithelial cells of the respiratory and 
gastrointestinal tracts resistant to viral infections. J Virol (2010) 84 (11):5670-7. doi: 10.1128/jvi.00272-10

83. Kotenko SV, Rivera A, Parker D, Durbin JE. Type III IFNs: Beyond antiviral protection. Semin Immunol (2019) 43:101303. doi: 10.1016/j.smim.2019.101303

84. Pott J, Mahlakoiv T, Mordstein M, Duerr CU, Michiels T, Stockinger S, et al. IFN-lambda determines the intestinal epithelial antiviral host defense. Proc Natl Acad Sci U S A (2011) 108(19):7944-9. doi: 10.1073/pnas.1100552108

85. Fung KY, Mangan NE, Cumming H, Horvat JC, Mayall JR, Stifter SA, et al. Interferon-epsilon protects the female reproductive tract from viral and bacterial infection. Science (New York NY) (2013) 339(6123):1088-92. doi: $10.1126 /$ science. 1233321

86. Stifter SA, Matthews AY, Mangan NE, Fung KY, Drew A, Tate MD, et al. Defining the distinct, intrinsic properties of the novel type I interferon, IFN. J Biol Chem (2018) 293(9):3168-79. doi: 10.1074/jbc.M117.800755

87. Couret J, Tasker C, Kim J, Sihvonen T, Fruitwala S, Quayle AJ, et al. Differential regulation of IFNalpha, IFNbeta and IFNepsilon gene expression in human cervical epithelial cells. Cell Biosci (2017) 7:57. doi: 10.1186/ s13578-017-0185-z

88. Nardelli B, Zaritskaya L, Semenuk M, Cho YH, LaFleur DW, Shah D, et al. Regulatory effect of IFN-kappa, a novel type I IFN, on cytokine production by cells of the innate immune system. J Immunol (Baltimore Md: 1950) (2002) 169(9):4822-30. doi: 10.4049/jimmunol.169.9.4822

89. Harris BD, Schreiter J, Chevrier M, Jordan JL, Walter MR. Human Interferon- $\varepsilon$ and interferon-kappa exhibit low potency and low affinity for cell surface IFNAR and the poxvirus antagonist B18R. J Biol Chem (2018) 293(41):16057-68. doi: 10.1074/jbc.RA118.003617

90. Miknis ZJ, Magracheva E, Li W, Zdanov A, Kotenko SV, Wlodawer A. Crystal structure of human interferon-lambdal in complex with its highaffinity receptor interferon-lambdaR1. J Mol Biol (2010) 404(4):650-64. doi: 10.1016/j.jmb.2010.09.068

91. Yoon SI, Jones BC, Logsdon NJ, Harris BD, Deshpande A, Radaeva S, et al. Structure and mechanism of receptor sharing by the IL-10R2 common chain. Structure (2010) 18(5):638-48. doi: 10.1016/j.str.2010.02.009

92. Dellgren C, Gad HH, Hamming OJ, Melchjorsen J, Hartmann R. Human interferon-lambda3 is a potent member of the type III interferon family. Genes Immun (2009) 10(2):125-31. doi: 10.1038/gene.2008.87

93. Terczyńska-Dyla E, Bibert S, Duong FHT, Krol I, Jørgensen S, Collinet E, et al. Reduced IFN $\lambda 4$ activity is associated with improved HCV clearance and reduced expression of interferon-stimulated genes. Nat Commun (2014) 5(1):5699. doi: 10.1038/ncomms6699

94. Ge D, Fellay J, Thompson AJ, Simon JS, Shianna KV, Urban TJ, et al. Genetic variation in IL28B predicts hepatitis C treatment-induced viral clearance. Nature (2009) 461(7262):399-401. doi: 10.1038/nature08309

95. Tanaka Y, Nishida N, Sugiyama M, Kurosaki M, Matsuura K, Sakamoto N, et al. Genome-wide association of IL28B with response to pegylated interferon-alpha and ribavirin therapy for chronic hepatitis C. Nat Genet (2009) 41(10):1105-9. doi: 10.1038/ng.449

96. Suppiah V, Moldovan M, Ahlenstiel G, Berg T, Weltman M, Abate ML, et al. IL28B is associated with response to chronic hepatitis C interferon-alpha and ribavirin therapy. Nat Genet (2009) 41(10):1100-4. doi: 10.1038/ng.447

97. Hamming OJ, Terczyńska-Dyla E, Vieyres G, Dijkman R, Jørgensen SE, Akhtar $\mathrm{H}$, et al. Interferon lambda 4 signals via the IFN $\lambda$ receptor to regulate antiviral activity against HCV and coronaviruses. EMBO J (2013) 32 (23):3055-65. doi: 10.1038/emboj.2013.232

98. Meager A, Visvalingam K, Dilger P, Bryan D, Wadhwa M. Biological activity of interleukins-28 and -29: comparison with type I interferons. Cytokine (2005) 31(2):109-18. doi: 10.1016/j.cyto.2005.04.003

99. Mendoza JL, Escalante NK, Jude KM, Sotolongo Bellon J, Su L, Horton TM, et al. Structure of the IFN $\gamma$ receptor complex guides design of biased agonists. Nature (2019) 567(7746):56-60. doi: 10.1038/s41586-019-0988-7

100. Thomas C, Moraga I, Levin D, Krutzik PO, Podoplelova Y, Trejo A, et al. Structural linkage between ligand discrimination and receptor activation by type I interferons. Cell (2011) 146(4):621-32. doi: 10.1016/j.cell.2011.06.048

101. Walter MR, Windsor WT, Nagabhushan TL, Lundell DJ, Lunn CA, Zauodny PJ, et al. Crystal structure of a complex between interferon-gamma and its soluble high-affinity receptor. Nature (1995) 376(6537):230-5. doi: 10.1038/ $376230 \mathrm{a} 0$
102. Walter MR. The molecular basis of IL-10 function: from receptor structure to the onset of signaling. Curr Topics Microbiol Immunol (2014) 380:191-212. doi: 10.1007/978-3-662-43492-5_9

103. Mao X, Ren Z, Parker GN, Sondermann H, Pastorello MA, Wang W, et al. Structural bases of unphosphorylated STAT1 association and receptor binding. Mol Cell (2005) 17(6):761-71. doi: 10.1016/j.molcel.2005.02.021

104. Chen X, Vinkemeier U, Zhao Y, Jeruzalmi D, Darnell JEJr., Kuriyan J. Crystal structure of a tyrosine phosphorylated STAT-1 dimer bound to DNA. Cell (1998) 93(5):827-39. doi: 10.1016/s0092-8674(00)81443-9

105. Krause CD, Lunn CA, Izotova LS, Mirochnitchenko O, Kotenko SV, Lundell DJ, et al. Signaling by covalent heterodimers of interferon-gamma. Evidence for onesided signaling in the active tetrameric receptor complex. J Biol Chem (2000) 275 (30):22995-3004. doi: 10.1074/jbc.M909607199

106. Gough DJ, Levy DE, Johnstone RW, Clarke CJ. IFNgamma signaling-does it mean JAK-STAT? Cytokine Growth Factor Rev (2008) 19(5-6):383-94. doi: 10.1016/j.cytogfr.2008.08.004

107. O’Donnell LA, Henkins KM, Kulkarni A, Matullo CM, Balachandran S, Pattisapu AK, et al. Interferon gamma induces protective non-canonical signaling pathways in primary neurons. J Neurochem (2015) 135(2):309-22. doi: $10.1111 /$ jnc. 13250

108. Ivashkiv LB. IFN $\gamma$ : signalling, epigenetics and roles in immunity, metabolism, disease and cancer immunotherapy. Nat Rev Immunol (2018) 18(9):545-58. doi: 10.1038/s41577-018-0029-z

109. Nathan CF, Murray HW, Wiebe ME, Rubin BY. Identification of interferongamma as the lymphokine that activates human macrophage oxidative metabolism and antimicrobial activity. J Exp Med (1983) 158(3):670-89. doi: $10.1084 /$ jem.158.3.670

110. Young HA, Bream JH. IFN-gamma: recent advances in understanding regulation of expression, biological functions, and clinical applications. Curr Topics Microbiol Immunol (2007) 316:97-117. doi: 10.1007/978-3540-71329-6_6

111. Dunn GP, Koebel CM, Schreiber RD. Interferons, immunity and cancer immunoediting. Nat Rev Immunol (2006) 6(11):836-48. doi: 10.1038/ nri1961

112. Alspach E, Lussier DM, Schreiber RD. Interferon $\gamma$ and Its Important Roles in Promoting and Inhibiting Spontaneous and Therapeutic Cancer Immunity. Cold Spring Harbor Perspect Biol (2019) 11(3):1-20. doi: $10.1101 /$ cshperspect.a028480

113. Zhang SY, Boisson-Dupuis S, Chapgier A, Yang K, Bustamante J, Puel A, et al. Inborn errors of interferon (IFN)-mediated immunity in humans: insights into the respective roles of IFN-alpha/beta, IFN-gamma, and IFNlambda in host defense. Immunol Rev (2008) 226:29-40. doi: 10.1111/j.1600065X.2008.00698.X

114. Chill JH, Quadt SR, Levy R, Schreiber G, Anglister J. The human type I interferon receptor: NMR structure reveals the molecular basis of ligand binding. Struct (Camb) (2003) 11(7):791-802. doi: 10.1016/S0969-2126(03) 00120-5

115. Nudelman I, Akabayov SR, Scherf T, Anglister J. Observation of intermolecular interactions in large protein complexes by $2 \mathrm{D}$-double difference nuclear Overhauser enhancement spectroscopy: application to the $44 \mathrm{kDa}$ interferon-receptor complex. J Am Chem Soc (2011) 133 (37):14755-64. doi: 10.1021/ja205480v

116. Nudelman I, Akabayov SR, Schnur E, Biron Z, Levy R, Xu Y, et al. Intermolecular interactions in a $44 \mathrm{kDa}$ interferon-receptor complex detected by asymmetric reverse-protonation and two-dimensional NOESY. Biochemistry (2010) 49(25):5117-33. doi: 10.1021/bi100041f

117. Piehler J, Schreiber G. Mutational and structural analysis of the binding interface between type I interferons and their receptor Ifnar2. J Mol Biol (1999) 294(1):223-37. doi: 10.1006/jmbi.1999.3230

118. Li Z, Strunk JJ, Lamken P, Piehler J, Walz T. The EM structure of a type I interferon-receptor complex reveals a novel mechanism for cytokine signaling. J Mol Biol (2008) 377(3):715-24. doi: 10.1016/j.jmb.2007.12.005

119. de Weerd NA, Vivian JP, Nguyen TK, Mangan NE, Gould JA, Braniff SJ, et al. Structural basis of a unique interferon-beta signaling axis mediated via the receptor IFNAR1. Nat Immunol (2013) 14(9):901-7. doi: 10.1038/ni.2667

120. Kalie E, Jaitin DA, Podoplelova Y, Piehler J, Schreiber G. The stability of the ternary interferon-receptor complex rather than the affinity to the individual 
subunits dictates differential biological activities. J Biol Chem (2008) 283 (47):32925-36. doi: 10.1074/jbc.M806019200

121. Levin D, Schneider WM, Hoffmann HH, Yarden G, Busetto AG, Manor O, et al. Multifaceted activities of type I interferon are revealed by a receptor antagonist. Sci Signal (2014) 7(327):ra50. doi: 10.1126/scisignal.2004998

122. Krause CD, Digioia G, Izotova LS, Xie J, Kim Y, Schwartz BJ, et al. Ligandindependent interaction of the type I interferon receptor complex is necessary to observe its biological activity. Cytokine (2013) 64(1):286-97. doi: 10.1016/j.cyto.2013.06.309

123. Wilmes S, Beutel O, Li Z, Francois-Newton V, Richter CP, Janning D, et al. Receptor dimerization dynamics as a regulatory valve for plasticity of type I interferon signaling. J Cell Biol (2015) 209(4):579-93. doi: 10.1083/ jcb.201412049

124. You C, Marquez-Lago TT, Richter CP, Wilmes S, Moraga I, Garcia KC, et al. Receptor dimer stabilization by hierarchical plasma membrane microcompartments regulates cytokine signaling. Sci Adv (2016) 2(12): e1600452. doi: 10.1126/sciadv.1600452

125. Sharma N, Longjam G, Schreiber G. Type I Interferon Signaling Is Decoupled from Specific Receptor Orientation through Lenient Requirements of the Transmembrane Domain. J Biol Chem (2016) 291 (7):3371-84. doi: 10.1074/jbc.M115.686071

126. van Pesch V, Lanaya H, Renauld JC, Michiels T. Characterization of the murine alpha interferon gene family. J Virol (2004) 78(15):8219-28. doi: 10.1128/jvi.78.15.8219-8228.2004

127. Hughes AL. The evolution of the type I interferon gene family in mammals. J Mol Evol (1995) 41(5):539-48. doi: 10.1007/bf00175811

128. Hughes AL, Roberts RM. Independent origin of IFN-alpha and IFN-beta in birds and mammals. J Interferon Cytokine Res (2000) 20(8):737-9. doi: 10.1089/10799900050116444

129. van Pesch V, Michiels T. Characterization of interferon-alpha 13, a novel constitutive murine interferon-alpha subtype. J Biol Chem (2003) 278 (47):46321-8. doi: 10.1074/jbc.M302554200

130. Oritani K, Medina KL, Tomiyama Y, Ishikawa J, Okajima Y, Ogawa M, et al. Limitin: An interferon-like cytokine that preferentially influences Blymphocyte precursors. Nat Med (2000) 6(6):659-66. doi: 10.1038/76233

131. Wang BX, Fish EN. Global virus outbreaks: Interferons as 1st responders. Semin Immunol (2019) 43:101300. doi: 10.1016/j.smim.2019.101300

132. Zhou Q, Chen V, Shannon CP, Wei XS, Xiang X, Wang X, et al. Interferon$\alpha 2 b$ Treatment for COVID-19. Front Immunol (2020) 11:1061. doi: 10.3389/ fimmu.2020.01061

133. Felsenstein S, Herbert JA, McNamara PS, Hedrich CM. COVID-19: Immunology and treatment options. Clin Immunol (Orlando Fla) (2020) 215:108448. doi: 10.1016/j.clim.2020.108448
134. Wu Z, McGoogan JM. Characteristics of and Important Lessons From the Coronavirus Disease 2019 (COVID-19) Outbreak in China: Summary of a Report of 72314 Cases From the Chinese Center for Disease Control and Prevention. Jama (2020) 323(13):1239-42. doi: 10.1001/ jama.2020.2648

135. Jaitin DA, Roisman LC, Jaks E, Gavutis M, Piehler J, Van der Heyden J, et al. Inquiring into the differential action of interferons (IFNs): an IFNalpha2 mutant with enhanced affinity to IFNAR1 is functionally similar to IFN-beta. Mol Cell Biol (2006) 26(5):1888-97. doi: 10.1128/ MCB.26.5.1888-1897.2006

136. Kalie E, Jaitin DA, Abramovich R, Schreiber G. An interferon alpha2 mutant optimized by phage display for IFNAR1 binding confers specifically enhanced antitumor activities. J Biol Chem (2007) 282(15):11602-11. doi: 10.1074/jbc.M610115200

137. Brideau-Andersen AD, Huang X, Sun SC, Chen TT, Stark D, Sas IJ, et al. Directed evolution of gene-shuffled IFN-alpha molecules with activity profiles tailored for treatment of chronic viral diseases. Proc Natl Acad Sci U S A (2007) 104(20):8269-74. doi: 10.1073/pnas.0609001104

138. Forero A, Ozarkar S, Li H, Lee CH, Hemann EA, Nadjsombati MS, et al. Differential Activation of the Transcription Factor IRF1 Underlies the Distinct Immune Responses Elicited by Type I and Type III Interferons. Immunity (2019) 51(3):451-64.e6. doi: 10.1016/j.immuni.2019.07.007

139. Porritt RA, Hertzog PJ. Dynamic control of type I IFN signalling by an integrated network of negative regulators. Trends Immunol (2015) 36 (3):150-60. doi: 10.1016/j.it.2015.02.002

140. Ivashkiv LB, Donlin LT. Regulation of type I interferon responses. Nat Rev Immunol (2014) 14(1):36-49. doi: 10.1038/nri3581

141. Francois-Newton V, Magno de Freitas Almeida G, Payelle-Brogard B, Monneron D, Pichard-Garcia L, Piehler J, et al. USP18-based negative feedback control is induced by type I and type III interferons and specifically inactivates interferon alpha response. PLoS One (2011) 6(7): e22200. doi: 10.1371/journal.pone.0022200

Conflict of Interest: The author declares that the research was conducted in the absence of any commercial or financial relationships that could be construed as a potential conflict of interest.

Copyright $(2020$ Walter. This is an open-access article distributed under the terms of the Creative Commons Attribution License (CC BY). The use, distribution or reproduction in other forums is permitted, provided the original author(s) and the copyright owner(s) are credited and that the original publication in this journal is cited, in accordance with accepted academic practice. No use, distribution or reproduction is permitted which does not comply with these terms. 